\title{
A FILOSOFIA PRIMEIRA DE DESCARTES SEGUNDO MICHEL HENRY*
}

\author{
Wojciech Starzynski**
}

\section{RESUMO}

O pensamento de Michel Henry impõe-se como único na corrente das interpretações fenomenológicas de Descartes. De fato, parece que nenhum dos fenomenólogos forneceu uma leitura tão completa dos textos de Descartes, indo muito além da tradição clássica dos fenomenólogos cuja análise cartesiana resume-se muitas vezes a um comentário bastante sumário e técnico das duas primeiras Meditações. Além disso, Henry, de uma maneira compatível com a tradição husserliana, busca apreender primeiro o pensamento próprio a Descartes, e depois tenta construir uma egologia fenomenológica que corresponde e ao mesmo tempo modifica aquela do autor das Meditationes. Vale observar que o reconhecimento de Descartes como autoridade fenomenológica tem seus limites e, de maneira próxima a Husserl, o autor de Essência da manifestação esboça um cenário segundo o qual o pai da modernidade afasta-se pouco a pouco da sua descoberta original. Em nosso trabalho, vamos tentar reconstruir a especificidade do cartesianismo henryano, nos concentrando na interpretação positiva da dúvida, do cogito; em seguida, colocaremos a questão das vias cartesianas pelas quais se poderia avançar as aquisições iniciais.

Palavras-Chave : Descartes. Filosofia Primeira. Fenomenologia. Michel Henry.

\footnotetext{
* Tradução de Polyana Tidre e Emmanuel Pillet.

** Pesquisador do Institute of Philosophy and Sociology of the Polish Academic of Sciences. E-mail: wojciech.starzynski@entre.pl
} 


\section{RÉSUMÉ}

La pensée de Michel Henry s’impose comme unique dans le courant des interprétations phénoménologiques de Descartes. En effet, il semble qu'aucun des phénoménologues n'a pas fournit une lecture tellement complète des textes de Descartes, allant bien au-delà de la tradition classique des phénoménologues dont l'analyse cartésienne se résume souvent en commentaire assez sommaire et technique des deux premières Méditations. Par ailleurs, Henry, d'une manière compatible avec la tradition husserlienne, cherche à saisir d'abord la pensée propre de Descartes, puis il essaie de construire une egologie phénoménologique à la fois correspondante et modifiante celle de l'auteur des Meditationes. Il faut remarquer que la reconnaissance de Descartes en tant que l'autorité phénoménologique a ses limites, et, d'une manière proche à Husserl, l'auteur de Essence de la manifestation esquisse un scénario selon lequel le père de la modernité se détourne peu à peu de sa découverte originale. Dans notre propos, nous allons essayer de reconstruire la spécificité du cartésianisme henryenne, en nous concentrant sur la interprétation positive du doute, du cogito, ensuite on posera la question des voies cartésiennes sur lesquelles on pourrait avancer les acquis de départ.

Mots clé: Descartes. Philosophie première. Phénoménologie. Michel Henry.

\section{Abertura do debate cartesiano com Heidegger e Husserl}

O momento cartesiano em Henry anuncia-se já na frase de abertura de seu primeiro livro, publicado em 1963, A essência da manifestação. Na sua introdução, ele coloca o problema, sem dúvida, ligado à história da filosofia moderna e contemporânea, "o problema do ser do ego e as pressuposições fundamentais da ontologia." No âmbito desta questão,

${ }^{1}$ A essência da manifestação, Paris: Puf, 1963, p. 1. 
Henry cita a famosa frase de Sein und Zeit de Heidegger, que vê na obra de Descartes, de um lado, uma descoberta nova da subjetividade, mas que, de outro lado, estigmatiza a indeterminação do cogito, quando se trata de seu estatuto ontológico. Segundo essa posição, Descartes teria finalmente deixado de tematizar o cogito como subjetividade ontológica, ao reconhecê-la imediatamente como res cogitans e, consequentemente, como uma substância que, por sua vez, inscreveria o cogito nos esquemas já preparados da ontologia medieval.

Todavia, parece que o cartesianismo fenomenológico de Michel Henry, de maneira ainda mais significativa que em relação à ontologia fundamental de Heidegger, foi influenciado pela "filosofia primeira" de Husserl, a qual o conduz à formulação da sua própria posição. Retornando à problemática cartesiana com grande força nos anos de 1980, o interesse de Henry por Descartes pode ser desde então considerado como uma retomada da tese husserliana acerca da posição excepcional do pensamento de Descartes no que se diz respeito à sua filosofia primeira, no sentido da determinação do ponto de partida fenomenológico. É assim que Husserl, a partir de A idéia da fenomenologia: Cinco lições, através de Filosofia primeira e das Meditações cartesianas até a Crise, reconhece o caráter único de Descartes na história da filosofia. $\mathrm{O}$ fundador da fenomenologia se concentra na possibilidade da apropriação fenomenológica da intuição, segundo sua opinião, genial das duas primeiras Meditações, e, mais particularmente, do procedimento da dúvida, que para o fenomenólogo se torna uma forma da redução fenomenológica e, por conseguinte, para chegar à fundação do cogito. Henry, sem dúvida, aproveita a visão husserliana da história da filosofia e compartilha de sua admiração pela profundidade extraordinária da descoberta cartesiana, da qual o autor não poderia nem mesmo estar plenamente consciente eà qual ele finalmente renuncia. Contudo, Michel Henry reconhece igualmente que o próprio Husserl, em razão de suas hipóteses (trata-se sobretudo da questão da intencionalidade como princípio diretor da fenomenologia), não apenas foi incapaz de aproveitar plenamente a inspiração cartesiana, mas, além 
disso, em função de sua crítica, obscureceu a força e a significação intrínsecas do cogito fenomenológico cartesiano atingido pela redução fenomenológica. É também o caso de Heidegger, que, em sua atitude crítica para com Descartes, confundiu as teses deste último com aquelas de Husserl. No entanto, isso não significa uma derrota da fenomenologia enquanto tal, mas, ao contrário, uma oportunidade. Essa possibilidade pode ser aproveitada à condição de que se reconheça que "o cogito de Descartes constitui a certidão de nascimento da própria fenomenologia". ${ }^{2}$ Em outros termos, é somente no nível da fenomenologia que o cogito cartesiano pode ser concebido e pensado em seu sentido próprio. $\mathrm{O}$ importante, todavia, é que isso significa também a necessidade da transformação da própria fenomenologia, que ainda não foi capaz de cumprir essa tarefa.

A fenomenologia husserliana ou heideggeriana, chamo-a de fenomenologia histórica. Ainda que ela reivindique sua origem de Descartes e, notadamente, do cogito, ou que, pelo contrário, ela o critique explicitamente, nos dois casos, essa fenomenologia não conseguiu perceber o que está em jogo no cogito. Somente uma fenomenologia ideal está em condições de apreendê-lo na sua radicalidade $(\ldots.){ }^{3}$

Assim, o filósofo assume uma tarefa muito ambiciosa. Notemos que, para fazer a ligação entre a importância de Descartes na história da filosofia e a formulação de uma nova fenomenologia, Henry radicaliza e esclarece a questão muitas vezes confusa do cartesianismo fenomenológico.

\section{A filosofia cartesiana do "começo"}

Nesta pesquisa, nos concentramos na maneira pela qual Henry

\footnotetext{
${ }^{2}$ HENRY, Michel. Fenomenologia da vida, Da subjetividade. Paris: Puf, 2003, p. 89. ${ }^{3}$ Ibidem, p. 90.
} 
interpreta a atitude cartesiana da dúvida e sua consequência sob a forma da descoberta do princípio do cogito. De imediato, convém notar a maneira proposta por Henry para trabalhar com textos históricos de Descartes. Ora, de acordo com o modelo husserliano, tratar-se-á certamente de excluir "o conteúdo dogmático do cartesianismo e de suas teorias", 4 com o objetivo de trazer à luz teses propriamente fenomenológicas. Em seguida, sempre de acordo com o fundador da "fenomenologia histórica", Henry tentará buscar no texto cartesiano "a teleologia imanente da idéia de fenomenologia". 5 Sendo isso possível, o fenomenólogo francês assinala uma dificuldade com a qual devemos deparar-nos ao considerarmos o que é o cogito. Por um lado, podemos insistir na análise de um "movimento de pensamento que procede através de uma série de implicações e de evidências, visando determinar uma certa realidade", ${ }^{6}$ que levará os potenciais pesquisadores ao estudo "histórico, social, psicanalítico, mas, primeiramente, gramatical, lógicogramatical, lógico-matemático, pois, em todo caso, trata-se de um texto"? Por outro lado, o objetivo da fenomenologia, que se identifica à meta posta por Henry, é apreender a realidade descrita por Descartes nas Meditações, a saber, a essência do pensamento. Tal abordagem do problema necessariamente desloca o centro da análise em direção ao momento da descoberta do cogito (Segunda Meditação) deixando de lado o caminho da dúvida (Primeira Meditação). Todavia, para Henry, a dúvida como figura preliminar do cogito é igualmente visada, mas apenas na medida em que ela convém com o programa assim definido. Denunciando uma dramaticidade ou uma fabularidade do cogito cartesiano, Henry, contudo, não os qualifica como erro, mas antes como um obstáculo possível à apreensão efetiva da estrutura fenomenológica necessária, que é no cogito visada.

\footnotetext{
${ }^{4}$ Ibidem, p. 68.

${ }^{5}$ Ibidem, p. 57.

${ }^{6}$ Ibidem, p. 90.

${ }^{7}$ Ibidem, nota 1 .
} 
Como caraterizar a leitura henryana de Descartes? Considerando suas várias conferências sobre o cartesianismo fenomenológico, contidas principalmente no volume II da reunião de artigos Fenomenologia da vida, intitulado Da subjetividade, e sua versão mais completa contida na primeira parte da Genealogia da Psicanálise, todas essas diversas tentativas buscam tratar Descartes como pensador da "filosofia do começo". Esse termo evidentemente nos faz pensar na noção cartesiana da filosofia primeira, já adaptada para seu uso fenomenológico por Husserl. O próprio Henry indica três componentes do "começo" cartesiano. Primeiramente, trata-se de realizar a redução fenomenológica ao aparecer puro, o que, em segundo lugar, é feito negativamente pela "colocação fora de jogo do ente". ${ }^{8}$ Os dois primeiros momentos juntam-se de fato numa distinção fundamental, expressa na linguagem de Descartes como aquela da alma e do corpo. O terceiro momento, que é a realização da "filosofia do começo", corresponde à própria descoberta do cogito. Para Henry, a formulação última desse cogito é a expressão videre videor, o que marca, aliás, sua originalidade em relação à leitura cartesiana.

Tentemos seguir o caminho cartesiano assim esboçado, tomando por fio condutor o texto Genealogia da psicanálise. Como já havíamos indicado, o que distingue Descartes dos outros filósofos, segundo Husserl e Henry, é a radicalidade do seu projeto da filosofia primeira. Descartes dizia que o ponto de partida do pensamento filosófico é não somente possível de ser atingido, mas necessário à prática da verdadeira filosofia. Como entender esse "ponto de partida"? Certamente, Descartes estava bem consciente de que seu projeto representava uma mudança essencial na filosofia. Todavia, o sentido mencionado pelos dois fenomenólogos é mais profundo e consiste em atingir algo de originário. Trata-se de "um passo para trás" dado de maneira a nos indicar o que é a filosofia e como ela deve proceder. Henry indica aqui um paradoxo, segundo o qual esse passo em direção ao originário se efetua através de uma atitude de "nemo

\footnotetext{
${ }^{8}$ Ibidem, p. 59.
} 
ante $m e "$, o que quer dizer que tal tarefa deveria ser assumida como se ninguém nunca a houvesse realizado antes. Assim, o acesso ao ponto de partida depende inteiramente da subjetividade, mesmo se a subjetividade quer dizer aqui a abertura do domínio ontológico do aparecer. Quais são as consequências de tal tese? De uma certa maneira, é verdade que a filosofia deve começar pela questão do ser, contudo, o que é a contribuição cartesiana essencial para a história da filosofia, é a tese segundo a qual esse ser aparece sempre no domínio da subjetividade. Precisamos então examinar as relações entre os três termos: do ser, do aparecer, e da subjetividade, que frequentemente povoam os debates tradicionais, tanto na filosofia em geral, quanto na fenomenologia. Pautando-se pela autoridade de Descartes, Henry declara que "somente o aparecer constitui a inicialidade do começo, não enquanto ele molda o parecer da coisa e sua vinda começante ao ser: um tal começo ainda é apenas o começo do ente. $\mathrm{O}$ aparecer é inicial, no sentido mais original, enquanto primeiro aparece ele próprio e nele próprio". ${ }^{9}$ Podemos perguntar-nos qual é a relação dessa frase enigmática com a filosofia primeira de Descartes. Segundo o fenomenólogo, o termo aparecer não é senão a cogitatio cartesiana, o que significa uma esfera primordial de pensar, claramente designada pela dúvida. A dúvida consiste na "rejeição das coisas e de sua aparência, com as quais elas são sempre mais ou menos misturadas e confundidas na consciência ordinária, para não mais considerar senão esse aparecer puro, abstração feita de tudo o que aparece nela". ${ }^{10}$ Podemos então concluir que o termo "aparecer" designa um solo original sobre o qual Descartes se movimenta e sobre o qual o termo "ser" adquire seu verdadeiro sentido. A "inicialidade" do aparecer constitui então uma diferença ontológica entre o aparecer e aquilo que aparece no seu campo. Segundo Henry, antes que todo ser chegue ao domínio da consciência, é o aparecer que o supõe e o precede. $\mathrm{O}$ importante para a especificidade

\footnotetext{
${ }^{9}$ Genealogia da Psicanálise. Paris: Puf, 1985, p. 18.

${ }^{10}$ Ibidem, p. 19.
} 
dessa interpretação de Descartes é que esse campo do aparecer precede a invenção do cogito e, na verdade, já está contido na própria dúvida, que constitui a própria redução fenomenológica. O puro aparecer é o resultado de um procedimento de pôr em dúvida, que se direciona ao "início" de tal maneira que, em si, na sua própria subjetividade, distinguese um certo momento do "aparecer" que condiciona a aparição de algo qualquer. Nota-se que Henry, muito rapidamente, coloca em questão as longas análises husserlianas, que se esforçam em identificar esse campo original ao Eu transcendental. Ele rejeita do mesmo modo a solução heideggeriana do ser - de tal maneira que o ser no sentido fenomenológico é diretamente acessível ao nível "subjetivo" do aparecer. O que se segue é que a intuição genial de Descartes consistia na determinação do cogito como o fundamento ontológico. Na fórmula cartesiana "Eu penso, eu sou", encontramos os momentos que nos interessam, a saber, aquele do aparecer original (penso), da subjetividade (eu) e o momento ontológico do ser dado (sou). Assim, a famosa objeção de Heidegger, segundo a qual o cogito, em sua indeterminação, não leva em conta suas pressuposições ontológicas, não mais se sustenta. Para Henry, é o contrário que ocorre: graças à operação da dúvida, alcançamos a esfera purificada do aparecer, que não constitui uma hipótese metafísica, mas o fato primário que se realiza na subjetividade. Nessa etapa inicial, o ponto já indicado na Essência da manifestação é atingido: a subjetividade identifica-se ao ser, se constituindo como uma camada originária, irredutível a qualquer outra, do aparecer. Nessa situação, da identificação da ordem ontológica, fenomenológica e egóica, seguindo Descartes, Henry dá prioridade ao nível fenomeno-ego-lógico que condiciona a ontologia. Segundo Henry, Descartes também o faz, na sua versão "canônica" do cogito, no cogito ergo sum, no qual a ligação pelo ergo deve ser entendida de uma maneira transitiva, a saber, que o ego, reconhecendo sua essência no "pensamento" (que é o aparecer), apenas secundariamente visa a questão: “eu sou?". Vale observar, todavia, que esse momento do aparecer intervém antes da apresentação do cogito e, portanto, ele se destaca no quadro da atitude 
da dúvida. Como acabamos de indicar, as etapas seguintes e, sobretudo, as razões particulares da dúvida são tratadas brevemente como acidentais pelo autor de Genealogia da psicanálise, podendo até mesmo causar erros consideráveis e obscurecer grandemente o próprio sentido do projeto. Podemos supor que a posição de Henry acerca da questão da dúvida cartesiana corresponde à de Husserl. Com essa diferença importante, a de que Henry parece concentrar-se unicamente no engajamento da vontade como uma posição tomada em relação à dúvida, enquanto Husserl examina atentamente a própria possibilidade de tal empreendimento, tendo como referência a subjetividade intencionalmente dirigida ao mundo. Henry, ao contrário, não vê necessidade de análise das condições prévias para o começo da filosofia, que deve encontrar sua validação na facticidade de sua efetuação pela vontade. No que concerne à dificuldade quanto à sua compreensão, segundo o fenomenólogo francês, a dúvida não consiste senão numa delimitação da esfera homogênea fenomenológica em relação àquilo que não o é. As etapas do procedimento dizem respeito ao arbitrário, pois não é necessário recorrer aos diferentes exemplos na ordem na qual eles são apresentados nas Meditationes. É importante destacar que, independentemente da possibilidade da ilusão, ou da confusão no sono ou da loucura, o fenômeno de redução a um puro aparecer sempre aparece na forma de "me parece que", então de aparecer. Henry admite, contudo, que a époché cartesiana não apenas "duvida de tudo, desta terra onde ele pisa e anda, de seu quarto e de tudo aquilo que ele vê, do mundo inteiro enfim, que não é senão uma ilusão e sonho", mas também exclui "o próprio Descartes, enquanto pertencendo a este mundo, enquanto homem, a [époché] diz respeito ao seu corpo, às suas pernas e aos seus olhos: nada de tudo isso existe."11

O erro fundamental na compreensão da dúvida seria então tomála como uma operação temporária que conduz à certeza. Nesse sentido, a dúvida não daria mais acesso à ordem ontológica, mas forneceria apenas

\footnotetext{
${ }^{11}$ Ibidem, p. 24.
} 
um conjunto arbitrário de opiniões sobre certas regiões do mundo, que se revelariam úteis à construção de uma outra estrutura, fundada dessa vez sobre a certeza atingida pelo contraste. "A certeza, que a sucede e na qual se transforma, não tem nada ver com o sum, é, ela também, um 'considerar que', um 'pensar que'." "Eu penso que eu sou com certeza porque, para que eu possa pensar, é preciso que eu seja" etc. O que conduz ao sum, o preâmbulo cartesiano do ser, é o aparecer que reina na dúvida como no "eu passeio, na medida em que é uma determinação da alma". ${ }^{2}$

Além de exercer a função de separação da esfera "alma" da esfera "corpo", o processo progressivo da dúvida indica igualmente o momento de determinação da essência da visão, com sua extensão característica que se desenvolve na medida da radicalização da époché. Na delimitação progressiva da esfera do aparecer em relação àquilo que não o é, colocase em dúvida primeiramente o domínio da visão sensível. Todavia, segundo uma outra tese de Descartes afirmando que a visão não pode ser de modo algum considerada essencialmente como um meio de abranger pelo órgão da visão, o domínio da visão junta-se também à visão matemática, cujos objetos, que aparecem segundo leis matemáticas e geométricas, tornamse igualmente duvidosos. Desse modo, Henry consegue explicar o problema da dúvida progressiva que atinge pouco a pouco o que difere da esfera original do aparecer.

Uma visão que não é aquela dos olhos é capaz de ver coisas completamente diferentes das pretendidas formas e cores, ela vê que dois mais três dão cinco, que num triângulo a soma dos ângulos é igual a dois retos etc. Ora, tudo isso pode ser falso, Descartes o supõe e, consequentemente, o afirma. No entanto, se tais conteúdos, claramente enxergados, são contudo falsos, tal não pode se dar senão porque a própria visão é falaciosa. ${ }^{13}$

\footnotetext{
${ }^{12}$ Ibidem, p. 23.

${ }^{13}$ Ibidem, p. 25.
} 
O caráter duvidoso da visão assim ampliada é definitivamente confirmado e radicalizado pela hipótese do gênio maligno. Para Henry, a dúvida hiperbólica significa a rejeição de toda relação cognitiva baseada na distância, no êxtase, ao mesmo tempo em que se afasta de uma dúvida baseada em tal ou qual razão arbitrária. "O ver produz-se no ek-stasis como uma apreensão que não é somente duvidosa e nebulosa, mas fundamentalmente errônea (se tal é a vontade do Maligno)". ${ }^{14}$ A dúvida no sentido de époché leva à conclusão de que a visibilidade não é autônoma na sua constituição e de que a essência da fenomenalidade, ou, para ir mais além, a essência da verdade, se encontra além. A visão aparece, ao contrário, como secundária em relação ao princípio do aparecer primitivo, que se confirma ele próprio por sua imediatidade. Assim, Henry vê no gesto cartesiano a rejeição avant la lettre do princípio da intencionalidade. Numa certa medida e indiretamente, a tese de Henry se confirma pela crítica de Husserl, que condena Descartes por ter negligenciado o sentido e a importância da intencionalidade. ${ }^{15}$

\section{Cogito como videor}

Os dois primeiros momentos do filósofo começante (o aparecer, a dúvida) acabam na formulação do cogito. Todavia, o que já é esboçado na análise do processo da dúvida, que, de um lado, é uma redução fenomenológica que é efetuada, mas de outro, nela Descartes busca obter a fundação para o todo o edifício das ciências, o que provoca uma duplificação de seus objetivos e obscurece a lógica de sua proposta, que finalmente resulta numa ambiguidade da noção central de sua filosofia, que é o cogito. No seu cartesianismo metodológico, Henry busca trazer à luz e desmascarar aquilo que ele chama de "a anfibologia" para apreender o momento próprio da descoberta fenomenológica de Descartes. Ao

\footnotetext{
${ }^{14}$ Ibidem, p. 27.

${ }^{15}$ Krisis, $\mathrm{xx}$.
} 
mesmo tempo e contrariamente às tentativas de Husserl de aproximação entre o cogito e o $E u$ transcendental, Henry tenta reencontrar no texto original de Descartes a continuidade e a coerência do pensamento inaugural do "pai da modernidade", que se torna para Henry o parceiro fenomenológico por excelência. A boa compreensão do princípio do cogito vem diretamente dos resultados da dúvida que elimina do campo original do pensamento tudo aquilo que é visível. Essa purificação do campo conduz à formulação do princípio que precede toda visão duvidosa, a saber, o princípio da subjetividade que se exprime no termo de videor. "O cogito acha sua formulação mais acabada na proposição videre videor : pareceme que vejo". ${ }^{16}$ Essa frase, a partir da qual Henry desenvolve sua interpretação de Descartes, aparece explicitamente nos dois textos cartesianos : o da Segunda Meditação e o dos Princípios da Filosofia. Resumindo o caminho em direção ao cogito cartesiano, Henry lembra que a dúvida se aplica ao filósofo enquanto homem situado no mundo e ele coloca a questão decisiva : "O que significa então ver, ouvir, sentir calor, para um ser que não possui olhos e que, além disso, talvez não exista ?". ${ }^{17} \mathrm{O}$ ego cartesiano, assim radicalmente separado do mundo, afirma a manifestação de um nível primitivo do aparecer que não pode mais ser reduzido, afirmando "At certe videre videor, audire, calescere", "Pelo menos, me parece que vejo, que ouço, que me esquento". ${ }^{18}$ Seguindo Descartes, Henry define o videor como "o aparecer primitivo, a capacidade original de aparecer e de se dar, em virtude da qual a visão se manifesta e se dá a nós, qualquer que seja a credibilidade e a veracidade que lhe convenha acordar enquanto

\footnotetext{
${ }^{16}$ Ibidem, p. 24.

${ }^{17}$ Ibidem.

${ }^{18}$ Meditatio II, AT VII, 29 ; IX, 23. A referência usada para os textos de Descartes é a edição Adam et Tannery (Oeuvres de Descartes, publiées par Charles Adam et Paul Tannery, 11 volumes, Paris, Vrin, 1996). Na notação simplificada usada internacionalmente, AT indica a edição; os numerais romanos, o volume; e os algarismos arábicos, o número da página.
} 
visão e o que quer que seja o que vê ou crê ver por seu próprio ver". ${ }^{19}$

\section{Sentio ergo sum}

O cogito concebido como videor rejeita o princípio segundo o qual a subjetividade no ato de reflexão se volta em direção a ela própria, se tornando o objeto de uma visão. A crítica do cogito reflexivo efetuada por Sartre e aprofundada por Merleau-Ponty é aqui sem dúvida em foco. Henry sustenta o caráter irrefletido do cogito, cuja modalidade fundamental torna-se a da sensação. Segundo o fenomenólogo, o cogito sob a figura do que sente é sua determinação a mais apropriada e, por conseguinte, caracteriza perfeitamente sua imanência subjetiva. Toda manifestação do fenômeno, sua aparição ou sua emergência será sempre associada a uma sensação. Além disso, todos os outros modos "extáticos" da subjetividade, como a compreensão ou a imaginação, são igualmente sempre acompanhados por um sentimento, nomeado por Henry de sentir primitivo e dele dependem. Do que, então, a fórmula do cogito pode ser assim esclarecida : "Sinto que penso, então sou " ${ }^{20} \mathrm{O}$ primado da sensação é igualmente confirmada no texto da Segunda Meditação, no qual, na frase que segue a fórmula videre videor, Descartes escreve : "Hoc falsum esse non potest ; hoc est proprie quod in me sentire appellatur ; atque hoc praecise sic sumptum nihil aliud est quam cogitare ", "E é propriamente o que em mim se chama sentir e isso, tomado assim precisamente, não é outra coisa senão pensar ". ${ }^{21}$ Graças à dúvida hiperbólica que faz uma abstração total do mundo exterior e de tudo que lhe é associado, não resta senão, se identificando ao sujeito, e também ao pensamento, o sentimento.

\footnotetext{
${ }^{19}$ Genealogia da psicanálise, 1985, p. 27.

${ }^{20}$ Ibidem, p. 29.

${ }^{21}$ Meditatio II, AT VII, 29 ; AT IX, 23.
} 
Nós já mencionamos a extensão dos textos fenomenológicos de Descartes, que são levados em conta pelo fenomenólogo francês. Convém notar dessa vez que, contrariamente a Husserl, cujo cartesianismo repousa quase exclusivamente em sua leitura das Meditações, indiretamente inspirado pelo texto das Regulae, a originalidade de Michel Henry se deve também ao fato de que, à parte os textos canônicos das Meditationes, ele segue de perto o caminho inicial da filosofia cartesiana descrito no texto Principia Philosophiae. É nesse texto que o privilégio do sentir no cogito se destaca de maneira ainda mais firme. Henry nota que, no momento que equivale à Segunda Meditação nos Principia Philosophiae, Descartes, em vez de recorrer à dúvida hiperbólica, retoma o exemplo de Hobbes, que, colocando em causa o princípio do cogito, declara poder dizer com a mesma certeza : "sum ambulans, ergo sum ". 22 No parágrafo 9 da primeira parte dos Princípios, Descartes escreve :

Nam si dicam: [...] ambulo, ergo sum, et hoc intelligam [...] de ambulatione, quae corpore peragitur, conclusio non est absolute certa, quia ut saepe in somnis, possum putare me [...] ambulare quamvis loco non movear, atque etiam forte, quamvis nullum habeam corpus. Sed si intelligam de ipso sensu sive conscientia [...] ambulandi, quia tunc refertur ad mentem, quae sola sentit sive cogitat se [...] ambulare. $^{23}$

${ }^{22}$ Objectiones tertiae, AT VII, 172.

${ }^{23}$ Principia I, 9, AT VIII, 7-8. "Pois se digo que [...] caminho e que infiro daí que sou ; se entendo que falo da ação que ocorre com minhas pernas, essa conclusão não é de tal forma infalível que eu não possa de nenhuma maneira dela duvidar, pois pode ocorrer que eu pense caminhar, mesmo que eu não saia do lugar; pois isso me ocorre algumas vezes, enquanto durmo, e o mesmo poderia ocorrer se eu não tivesse corpo: ao passo que, se entendo que falo somente da ação de meu pensamento ou do sentimento, quer dizer, do conhecimento que está em mim, que faz com que me pareça que eu ando, essa mesma conclusão é tão absolutamente verdadeira que não posso duvidar dela, em razão de sua referência à alma, que exclusivamente possui a faculdade de sentir" AT IX-2, 28. 
Esse texto é particularmente precioso à interpretação de Henry, pois a redução à imanência do sentimento subjetivo é feita aqui, sem recurso excessivo à fabularidade da dúvida, que mostra que ela não exige mais passos específicos de tal gênero, os quais podem ocultar seriamente a sua essência. Ao mesmo tempo, o que se torna bem mais importante é o fato de que o cogito, ilustrado por certas de suas atividades possíveis, que finalmente se reduzem simplesmente ao sentir, também lhe aparece profundamente constituído por essa dimensão. Assim, um paradoxo típico do sujeito cartesiano se desenha : realizando sua essência e sua identidade plena pelo ato simples de sensação corporal, ele mantém e confirma de modo fenomenológico a tese da diferença fundamental entre a alma e o corpo. A "alma" aparece não como fundamento ôntico, mas ontológico do pensamento, como "um lugar" onde surge a aparição primeira e original da sensação. Torna-se claro nesse contexto por que Descartes pensava a cogitatio como inseparavelmente ligada à consciência. No artigo citado, Descartes define a cogitatio como "illa omnia, quae nobis consciis in nobis sunt, quatenus eorum in nobis conscientia est", "tudo o que se faz em nós de tal modo que nós o percebemos imediatamente por nós mesmos ". ${ }^{24}$ Assim, a primeira etapa da egologia cartesiana reconstruída por Henry consiste na identificação do cogito com o modo de sentir. Em troca, o sentir que acompanha e sustenta a subjetividade mostra a própria essência do pensamento como a consciência de si imanente e desprovida de toda reflexividade.

O ponto característico das análises fenomenológicas do pensamento de Descartes é marcado pelo esforço de separação entre os temas fenomenológicos e os demais, que se confundem incessantemente com os primeiros. Sem dúvida, enquanto tese que obscurece as intuições fenomenológicas de Descartes, é necessário primeiramente mencionar o esforço de se construir o sistema (o edifício) das ciências objetivas à maneira de um sistema dedutivo. O que estigmatiza por sua vez o filósofo francês

${ }^{24}$ Ibidem, AT VII, 7; AT VIII-2, 28. 
é o fato de ter confundido a atitude da redução à imanência com a análise das ideias que visa ultrapassar essa imanência, passando do cogito ao cogitata. Entretanto, apesar da objeção segundo a qual Descartes como autor que no decorrer de sua meditação perde progressivamente as aquisições de sua descoberta original, Henry encontra no seu discurso ainda um outro argumento em favor do desenvolvimento da fenomenologia noética ou egológica. Não nos surpreende que, após ter reconhecido o privilégio do sentire no cogito, o autor de Genealogia da psicanálise busque fórmulas que poderiam provar o caráter originário e fundamental para a subjetividade nos termos da afetividade. Isso permitiria sustentar o cogito na medida em que fenomenológico como a afetividade imediata que assim se distingue de um cogito entendido como o fundamento dos cogitata e, portanto, o fundamento do conhecimento do mundo e das ciências objetivas. Henry coloca a seguinte questão : "Descartes se referiu em algum momento, ao menos uma única vez, à substância fenomenológica da aparição como se auto-atestando ela própria, como se autoapresentando ela própria tal como ela é, como o fundamento e a essência de toda verdade absoluta?". ${ }^{25}$

A essa questão, Henry encontra resposta no texto das Paixões da alma, no qual, de uma maneira realmente surpreendente, a problemática da influência do corpo sobre a alma pelo intermédio dos nervos e dos "espíritos animais", situando-se então "junto aos antípodas da redução", se encontra desviada, se abrindo desse modo às análises bem conhecidas das Meditações acerca da diferença entre o sonho e a vigília, que assim retoma a atitude da dúvida. Esse retorno, pensado no quadro das "paixões da alma", confirma e reforça o caráter irredutível à causalidade corporal do sentir. É justamente na sua afetividade própria que Henry vê a substancialidade fenomenológica, o que deveria ser entendido de tal maneira que é precisamente o caráter passional do pensamento que o determina, permitindo a manifestação do fenômeno independentemente

\footnotetext{
${ }^{25}$ Genealogia da psicanálise. Paris: Puf, 1985, p. 37.
} 
da variabilidade do estado físico do sono ou da vigília. O texto que faz referência a essa situação é uma passagem do artigo XXVI das Passiones animae, na qual Descartes nota que, ainda que por vezes possamos nos enganar, considerando como a percepção sensível verdadeira aquilo que aparece no sonho, ou em certos estados de vigília,

não podemos ser [enganados] do mesmo modo quanto às paixões, tanto mais que elas são tão próximas e tão interiores à nossa alma, que é impossível que as sinta sem que elas sejam verdadeiramente tais quais ela as sente. [...] ainda que dormíssemos e que sonhássemos, não poderíamos nos sentir tristes ou tomados por alguma outra paixão, sem que seja realmente verdadeiro que a alma possui em si essa paixão. ${ }^{26}$

Apesar das indicações positivas das passiones animae para a definição fenomenológica da subjetividade segundo seu modo de aparição a si mesma, Henry denuncia no pensamento de Descartes uma espécie de esquizofrenia ou, ao menos, uma grave inconsequência, que provoca a justaposição da atitude da redução à imanência, mantendo assim entre parênteses o corpo e seu pretenso impacto sobre a alma, com a explicação ôntica fundada sobre a causalidade física. Colocando fora de questão essas explicações "absurdas" que atestam o fenômeno da afetividade, Henry vê assim a possibilidade de permanecer na postura de redução, única que nos permite pensar a afetividade como modo autônomo e essencial do cogito. O próprio texto tardio de Descartes parece confirmar essa hipótese, pois, malgrado o naturalismo inicial, no fim das contas, o próprio filósofo “involuntariamente, sem dúvida, mas irrefutavelmente, é obrigado a reconhecer que a paixão em si, na sua efetividade fenomenológica, ou seja, na sua afetividade, não depende do corpo". ${ }^{27}$ Além disso, a análise das percepções "cuja causa reside na alma” (em

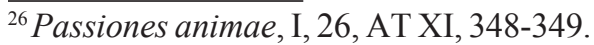

${ }^{27}$ Genealogia da psicanálise. Paris: Puf, 1985, p. 40.
} 
oposição às percepções físicas) anuncia a etapa seguinte sobre a via fenomenológica da determinação do cogito. O artigo XIX das Paixões da alma declara que, no caso da "percepção da alma", distingue-se um caso privilegiado de querer cuja essência será ao mesmo tempo sua "percepção" e uma "paixão interna”. Essa aproximação do querer e do sentir afetivo torna-se para Henry o exemplo paradigmático da subjetividade, que, segundo sua essência, faz abstração total de qualquer corpo, não fazendo nenhuma referência à exterioridade. Assim, trata-se do caráter fundamentalmente volitivo da subjetividade, que assim demonstra sua independência, no domínio passional, da influência das causas exteriores. Nesse sentido, a passio é considerada como “a apercepção original que dá [o conjunto das modalidades específicas do pensamento] a elas próprias na imediação". ${ }^{28} \mathrm{O}$ que assim se torna claro no caso da vontade, a saber, sua autonomia, Henry a atribui a todos os modos possíveis da afetividade subjetiva. Segundo o fenomenólogo, a pressão da própria coisa faz que, apesar do questionamento inicial acerca da autonomia do cogito que sente inscrito no sistema das causas físicas, a naturalização da subjetividade cede lugar ao sujeito afetivo, que na imediatidade de sua experiência a si nos conduz ao cogito das Meditações, aquele que surge da redução à imanência, na esfera fenomenológica do videor. Essa situação particular do querer que se identifica à apercepção interna dá ocasião ao autor de definir o cogito afetivo como princípio "que domina a oposição das 'ações' e das 'paixões', e que funda tanto umas quanto as outras". ${ }^{29}$ As análises da essência do cogito afetivo levam o filósofo novamente em direção ao texto das Meditações, levando desta vez em consideração a definição adequada do cogito.

Como bem o sabemos, a Segunda Meditação fornece duas definições do cogito. Primeiramente, Descartes define o cogito como uma res cogitans, sinônimo de alguns termos : mens, animus, intellectus,

\footnotetext{
${ }^{28}$ Ibidem.

${ }^{29}$ Ibidem, p. 41.
} 
ratio. Embora ele ainda não tenha decidido a definição exata desses termos, permanecendo no modo da redução, Descartes privilegia entretanto claramente, nessa definição provisória, o momento do pensamento racional. Henry reconhece que essa definição constitui uma tentativa de apreender a essência do cogito como o espírito que se serve principalmente da "luz natural'. Procedendo de tal maneira, em vez de desenvolver as descobertas que resultam da redução fenomenológica, Descartes parece referir-se à análise contida nas Regulae, cujo objetivo era construir uma teoria objetiva da ciência. Por conseguinte, a definição da essência da subjetividade se revela fenomenologicamente inútil e mesmo nociva, em razão da mudança da atitude precedentemente tomada. Henry suspeita até mesmo que o sentido da empresa cartesiana se modifique aqui de maneira sutil e que Descartes recua progressivamente da tarefa de desenvolvimento de sua "filosofia primeira". Todavia, na continuação do texto analisado, Descartes formula uma outra definição, aquela da res cogitans determinada dessa vez pela enumeração de vários modos do cogito, ela é então “dubitans, intelligens, affirmans, negans, volens, nolens, imaginans et sentiens". ${ }^{30} \mathrm{Tal}$ definição apreende o eidos da subjetividade ? A multiplicidade das modalidades pode suscitar a impressão do arbitrário. Entretanto, para Henry, tal enumeração testemunha a atitude da redução que, nesse estágio, exclui uma hierarquização. Assim, não será mais possível indicar um modo privilegiado do cogito a partir da segunda definição ? Ora, segundo o fenomenólogo francês, de maneira contrária ao privilégio da inteligência expresso na primeira definição, a segunda definição nos mostra o momento volitivo dominante que aparece nos cinco modos : dubitans, affirmans, negans, volens, nolens. O que significa que "o reconhecimento do aparecer em sua fulguração inicial, o reconhecimento da essência do pensamento e do ser, se realiza no cogito a partir da própria vontade, cuja dúvida não é senão uma modalidade". ${ }^{31}$

\footnotetext{
${ }^{30}$ Meditatio II, AT VII, 28.

${ }^{31}$ Genealogia da psicanálise. Paris: Puf, 1985, p. 48.
} 
Podemos concluir que a análise do cogito a partir da dúvida se efetiva pelo reconhecimento de seu modo privilegiado, que é aquele da vontade e não o da inteligência. Pois a dúvida, que faz abstração do mundo e assim libera a dimensão fenomenal do aparecer, se apresenta como uma forma radical de querer. Donde a dúvida praticada para alcançar o cogito no caminho da "filosofia primeira" se opõe à dúvida natural, que é justamente o trabalho do intellectus que apresenta a si próprio algumas razões específicas para duvidar. Ao contrário, a dúvida a partir da vontade é chamada por Descartes dúvida hiperbólica, o que significa que, em seu caráter extremo, ela é "contra natureza e contra a natureza do intelecto, contra a ratio". A experiência dessa hiperbolização torna possível um reconhecimento desse modo do querer como um modo infinito, sempre em oposição ao intelecto finito. Henry, se referindo evidentemente à Quarta Meditação, explica fenomenologicamente a tese da infinitude da vontade humana, introduzindo nela também a dimensão teológica,

a dúvida é um modo da vontade infinita, vontade que é em mim idêntica ao que ela é em Deus, da vontade que pode querer tudo o que ela quer, absolutamente, incondicionalmente e sem limite, que pode querer que o verdadeiro seja falso e que o ver, compreendido sob a forma da evidência, que nele repousa e se banha em sua luz, não o seja. ${ }^{32}$

\section{Conclusão}

Reconstruímos o curso do "caminho cartesiano" de Michel Henry pela evocação das diferentes teses cartesianas com as quais o filósofo francês se indentificou e graças às quais procurou desenvolver e validar sua própria posição filosófica nomeada fenomenologia material. Certamente não é necessário esquecer que o trabalho de Henry é acompanhado de

${ }^{32}$ Ibidem, p. 48. 
um número relativamente importante de considerações críticas, que mostram, exatamente como no caso de Husserl, um esforço para separar todos os elementos não fenomenológicos que obscurecem o verdadeiro fim filosófico do projeto cartesiano. No rastro dessas considerações poderíamos desenvolver as análises mais aprofundadas da crítica de Descartes, ou mais precisamente, deveríamos considerar a tese da "anfibologia" do pensamento cartesiano, que declara uma constante penetração dos dois momentos heterogêneos e irredutíveis um ao outro, até mesmo mutuamente exclusivos e em luta permanente, a saber, o momento fenomenológico da filosofia da imanência e o outro, baseado sobre o êxtase intencional. Além disso, neste artigo apenas mencionamos o momento "dialógico", ou melhor, "responsorial" do pensamento de Descartes, que, para Henry, toma uma forma de conflito essencial e radical entre a fenomenologia da imanência e o pensamento do êxtase representado em sua figura histórica por filósofos, tais como Hobbes ou Gassendi. Esperamos que esses problemas sejam logo submetidos a uma análise mais aprofundada.

Data de registro: $18 / 07 / 2011$ Data de aceite: $24 / 08 / 2011$ 